\title{
ESTUDO IN SILICO POR DOCKING MOLECULAR AVALIA INTERAÇÃO DE INIBIDORES DA ACETILCOLINESTERASE
}

\author{
Ketly dos Santos Nascimento ${ }^{1}$, Francisco Carlos de Medeiros Filho², Rafael \\ Medeiros de Lima $^{3}$, Willian Oliveira Santos ${ }^{4}$, Nilton Ferreira Frazão ${ }^{5}$
}

${ }^{1}$ Curso de Licenciatura em Física, Centro de Educação e Saúde, Universidade Federal de Campina Grande, Laboratório de Simulação Computacional e Modelagem de Nanomateriais, Cuité-PB, Brasil.

${ }^{2}$ Curso de Mestrado, Programa de Pós-Graduação Ciências Naturais e Biotecnologia, Universidade Federal de Campina Grande, Laboratório de Simulação Computacional e Modelagem de Nanomateriais, Cuité-PB, Brasil.

${ }^{3}$ Mestrado em Física, Programa de Pós-Graduação em Física, Universidade Federal de Alagoas, Laboratório de Simulação Computacional e Modelagem de Nanomateriais, Cuité-PB, Brasil.

${ }^{4}$ Mestrado em Física, Programa de Pós-Graduação em Física, Universidade Federal de Campina Grande, Laboratório de Simulação Computacional e Modelagem de Nanomateriais, Cuité-PB, Brasil.

${ }^{5}$ Professor Doutor da Unidade Acadêmica de Física e Matemática, Universidade Federal de Campina Grande, Laboratório de Simulação Computacional e Modelagem de Nanomateriais, Cuité-PB, Brasil.

Email para correspondência: nilton.frazao@ufcg.edu.br

\section{Resumo}

A doença de Alzheimer (DA) é o quadro mais comum de demência entre idosos, atingindo cerca de 50 milhões de pessoas em todo mundo. Através de pesquisas foi percebido 0 encolhimento do cérebro e a morte de neurônios colinérgicos, em decorrência há uma diminuição de acetilcolina em pacientes com DA. A enzima acetilcolinesterase tem o papel de hidrólise na degradação da acetilcolina, logo há um crescente interesse em fármacos que possam inibir sua ação, como no caso da rivastigmina e a da galantamina. Portanto, nosso trabalho teve como objetivo validar a eficácia desses fármacos, observando o comportamento ao formarem juntos um complexo. Com a utilização do docking molecular, podemos analisar as propriedades físico-químicas, afinidades eletrônicas, e então, quantificar o grau energético na interação proteína-ligante. A estrutura escolhida, trata-se de uma hidrolase de código 1ACJ, que foi modelada no Discovery Studio para que fossem retiradas as moléculas de água e adicionar os hidrogênios. Como resultado, foi visto que os dois ligantes apresentam interação considerável com a acetilcolinesterase, visto que os resultados apresentaram energias negativas. Para tal, analisou-se as ligações de Van der Waals, tipo pi e ligações de hidrogênio. A nuvem eletrostática confirma os resultados apresentando picos de densidade negativa nas vizinhanças. Dado o exposto, temos que os dois compostos apresentaram propriedades físicoquímicas capazes de atuar no Sistema Nervoso Central e inibir a ação enzimática.

Palavras chave: Docking molecular, proteína-ligante, acetilcolinesterase 


\begin{abstract}
Alzheimer's disease (AD) is the most common condition of dementia among the elderly, affecting around 50 million people worldwide. Through research it was noticed the shrinking of the brain and the death of cholinergic neurons, due to a decrease in acetylcholine in patients with $\mathrm{AD}$. The enzyme acetylcholinesterase has the role of hydrolysis in the degradation of acetylcholine, therefore, there is a growing interest in drugs that can inhibit its action, as in the case of rivastigmine and galantamine. Therefore, our work aimed to validate the effectiveness of these drugs, observing the behavior when forming a complex together. With the use of molecular docking, we can analyze the physical-chemical properties, electronic affinities, and then, quantify the energy degree in the protein-ligand interaction. The chosen structure is a hydrolase code $1 \mathrm{ACJ}$, which was modeled at Discovery Studio so that water molecules could be removed and the hydrogens added. As a result, it was seen that the two ligands show considerable interaction with acetylcholinesterase, since the results showed negative energies. For this purpose, the Van der Waals, pi, and hydrogen bonds were analyzed. The electrostatic cloud confirms the results by showing negative density peaks in the neighborhood. Given the above, we have that the two compounds showed physicochemical properties capable of acting on the Central Nervous System and inhibiting the enzymatic action.
\end{abstract}

Keywords: Molecular docking, protein-ligand, acetylcholinesterase

\title{
1 Introdução
}

Em todo o mundo, doenças associadas à demência atingiram 50 milhões de pessoas, sendo o Alzheimer a forma mais comum. O Alzheimer trata-se de uma doença neurodegenerativa sem causas que possam antecedê-las, como acidentes vasculares ou traumas, no entanto o cérebro do indivíduo poderá apresentar alterações muito antes que os primeiros sinais sejam percebidos. Nos estágios iniciais da doença, é comum as pessoas sentirem dificuldade em situações simples; saber onde guardou as chaves de casa ou até mesmo, esquecer uma panela no fogo. Com decorrer do processo, até as atividades mais simples do cotidiano começam a ser executadas com dificuldade, problemas com aprendizagem e até mesmo de linguagem (RANG et al., 2007). Esses sintomas se devem ao fato de que partes cerebrais que controlam as funções cognitivas e a memória passam a sofrer alterações, podendo, comprometer o sistema neural. Em estágios finais, esses pacientes passam a necessitar de cuidados especiais, pelo fato de não serem capazes de exercerem atividades básicas, como alimentação. Nessa etapa, a perda neural e os danos tornam-se irreversíveis, levando por fim à morte (Association, Alzheimer's 2019).

Doença de Alzheimer (DA), atinge principalmente a população idosa, onde pessoas com 65 anos tem um fator de risco de 5\% e um índice de $90 \%$ em pessoas com 95 anos, o que dificulta um diagnóstico precoce, pois muitos 
desses sintomas iniciais se assemelham a caraterísticas comuns de pessoas com mais idade. Mesmo ainda não estando claro as causas que levam a essa doença, há uma associação desta ao encolhimento do cérebro e a morte de neurônios colinérgicos, trazendo como característica a perda da memória de curto prazo. Algumas pesquisas relacionam essa perda neuronal, a formação de placas senis e os emaranhados neurofibrilares (RANG et al., 2007).

As placas senis são depósitos de material amiloides. Essas placas começam de forma não tóxica, no entanto em alguns indivíduos elas se alteram e passam a estar associadas a DA. Seu aumento é comum no processo de envelhecimento, no entanto, há um crescimento ainda maior em pessoas com Alzheimer. Essa alteração ocorre no decorrer do processo de clivagem no qual a enzima percursora $\beta$-amiloide, é realizado pela via $\beta$-secretase, e esses fragmentos então produzidos são tóxicos (ALMEIDA, 2011).

Os neurônios se comunicam através das sinapses que são geradas através de microtúbulos, a proteína Tau é responsável por mantê-los estabilizados. Em casos de anomalias, a Tau se desprende dos microtúbulos, fazendo com que esses se desestabilizem e até rompam. A proteína danificada se converte em filamentos torcidos, dando forma a emaranhados. Por decorrência desse processo, não haverá transporte de nutrientes e outros tipos de informação entre as células. (Association, Alzheimer's 2020).

Por consequência da perda de neurônios colinérgicos, estudos indicam que há uma diminuição da acetilcolina em pacientes com Alzheimer, um neurotransmissor que atua nas sinapses neurais. A enzima acetilcolinesterase tem o papel de hidrólise na degradação da acetilcolina. Com isso, há uma busca por medicamentos que possam inibir a ação da enzima acetilcolinesterase, e assim aumentar os níveis de acetilcolina no cérebro. Porém, esses anticolinesterásicos atuam apenas de forma terapêutica, não alterando o curso da doença.Os inibidores da colinesterase (figura 1) são um dos poucos fármacos aprovados para o tratamento da DA. Dentre eles temos a rivastigmina e a galantamina, ambos atuam como inibidores reversíveis da AchE (acetilcolinesterase). (HENRIQUE; BERTOLUCCI, 2000). 
O método de encaixe molecular, tem como vantagem agilizar os processos de descobrimento de novas drogas, ou até mesmo de validar sua eficácia prevista, com o objetivo de prever o modo de ligação e a afinidade entre pequenas moléculas e seus respectivos receptores. Tendo em vista que para desenvolvimento de um novo fármaco podia-se levar entre 10 a 20 anos, ferramentas tecnológicas como o docking é uma alternativa eficaz e econômica, (F. SOUSA et al., 2010).

Assim, conhecendo a proteína alvo, podemos validar a eficácia de fármacos já aprovados no mercado, observando o comportamento dessas estruturas ao formarem um novo complexo. Em nossa abordagem, traremos uma análise in silico, que através da técnica de atracamento molecular, é possível observar as propriedades físico-químicas, as afinidades eletrônicas, tipos de ligações envolvidas no processo, e assim, quantificar o grau energético na interação proteína ligante.

\section{Metodologia}

\subsection{Estrutura da acetilcolinesterase $1 \mathrm{ACJ}$}

Estrutura tridimensional da acetilcolinesterase de Torpedo californica (figura 1), trata-se de uma hidrolase determinada por cristalografia de raio-x, com uma resolução de $2,8 \AA$, onde posteriormente foi analisada pelo programa Discovery Studio, removemos o ligante, as moléculas de água e adicionamos os hidrogênios para assim completar a camada de valência. 




Figura 1 - Visualização 1ACJ

Fonte: Dados da pesquisa, 2020.

\subsection{Otimização}

Logo após a obtenção dos fármacos, foram levados para software Materials Studio Modeling, onde foi realizado o processo de refinamento das moléculas, sendo feitas otimizações clássicas e quânticas em todos os dois ligantes, com objetivo de obter uma conformação geométrica estável. Na primeira etapa do refinamento foi feita a otimização clássica, na qual são empregados conceitos da física clássica. Para isso foi utilizado o modo FORCITE, e assim encontrar as geometrias de menor energia, baseadas no algoritmo gradiente conjugado (LGA). Ainda no mesmo programa, no que se diz respeito às otimizações quânticas, utilizamos módulo DMOL3, onde foi empregada a aproximação do gradiente generalizado (GGA) e a aproximação de densidade local (LDA), levando em consideração todos os elétrons das moléculas (NASCIMENTO, 2015). 


\subsection{Docking molecular}

Para realizar o ancoramento, fizemos uso do software ArgusLab. De início realizamos um direcionamento das grades cúbicas, através dos códigos ArgusDock e GADock, a fim de obtermos uma melhor margem da localização do local de atracamento, onde as coordenadas escolhidas foram de $32,75 \mathrm{x}$ $28,75 \times 27 \AA$, e com um espaçamento de $0,400 \AA$. O local escolhido foi previamente visto no artigo que originou a estrutura enzimática (1GQR).

Utilizamos o algoritmo lamarkiano (LGA), para que fosse possível que o ligante buscasse a posição de encaixe mais favorável. Onze configurações foram obtidas entre os complexos proteína-ligante, sendo ranqueadas de acordo com as conformações de menor energias de ligação, os melhores resultados calculados foram visualizados pelo Discovery Studio.

\subsection{Rivastigmina}

A rivastigmina é um inibidor pseudo-reversível da acetilcolinesterase e da buritilcolinesterase. Este fármaco foi aprovado para o estágio leve a moderado da doença de Alzheimer. Embora seus mecanismos de ação ainda sejam desconhecidos, estudos mostram que a rivastigmina promove uma ação terapêutica, aumentando os níveis de acetilcolina por meio da inibição de sua hidrolase (DRUGBANK, 2020).

Em 2007, a rivastigmina foi reformulada via transdérmica (adesivo), com isso obtém-se uma diminuição dos efeitos colaterais como náuseas, vômitos, diarréia e dores abdominais (MEHTA, M. et al., 2012 \& ARQUES, L. A. et al.,2011). 


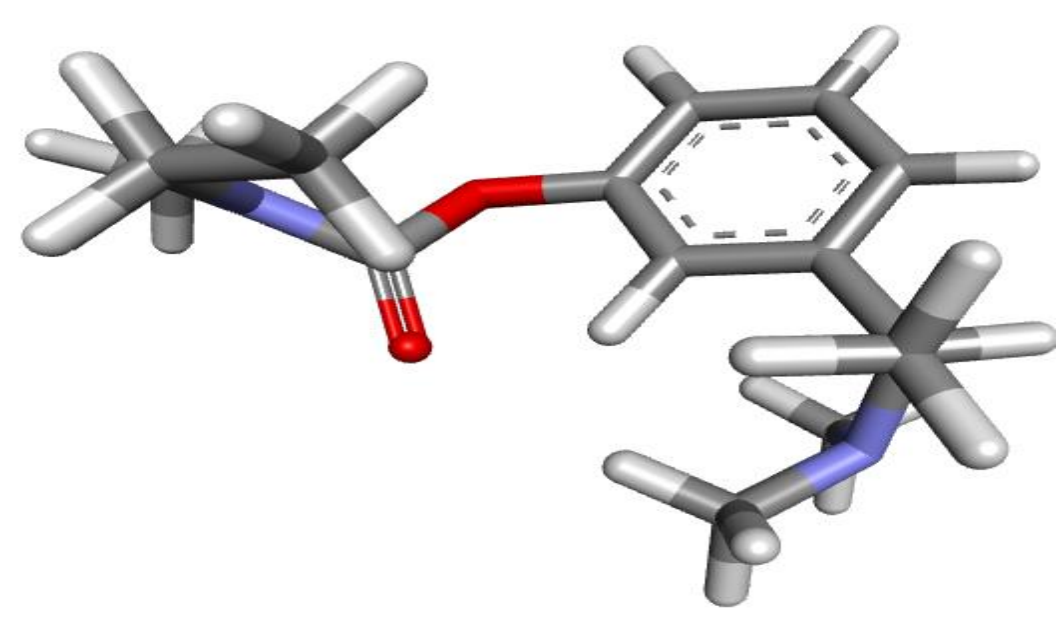

Figura 2. Estrutura da Rivastigmina no software Discorery Studios Visualizer Fonte: Dados da pesquisa, 2020.

\subsection{Galantamina}

A galantamina é um alcalóide natural da família dos lírios. Tem como mecanismo de ação inibir a Acetilcolinesterase de maneira competitiva e de forma rapidamente reversível. Além de ser utilizado nos tratamentos de Alzheimer, esse medicamento é indicado para tratar outros distúrbios do sistema nervoso central (DRUGBANK, 2020).

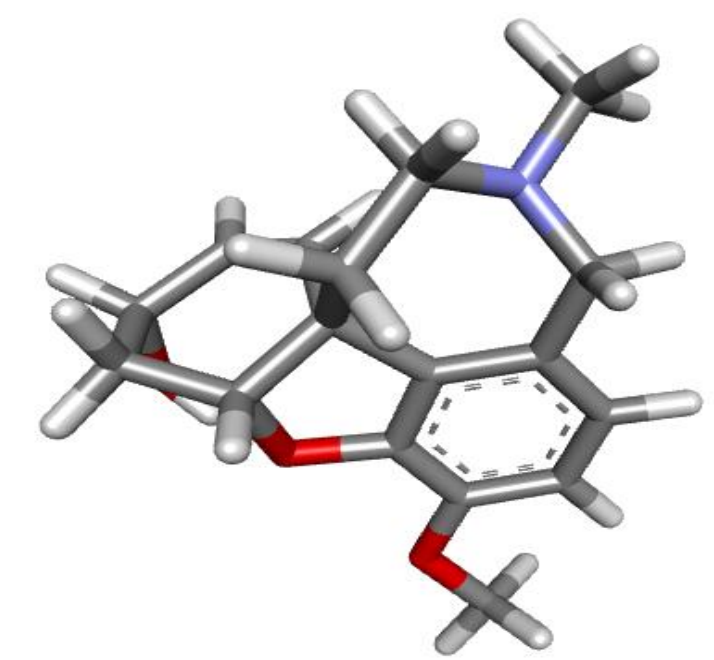

Figura 3. Estrutura da galantamina no software Discorery Studios Visualizer Fonte: Dados da pesquisa, 2020. 


\section{$3 \quad$ Resultados}

$\mathrm{Na}$ tabela I, selecionamos as onze melhores posições das energias livres de ligação, entre o receptor $1 \mathrm{ACJ}$ e o ligante (rivastigmina). No modo de encaixe escolhido, o ligante ancorou-se de forma flexível, pois dentre as três conformações oferecidas no programa de docking (torção, rígido e flexível), essa foi a que mostrou uma melhor interação, apresentando baixos valores energéticos.

$\mathrm{Em}$ todas as posições o complexo proteína-ligante apresentou resultados favoráveis, onde as energias negativas mostram que ocorre uma ligação atrativa entre os dois compostos. As energias foram obtidas em $\mathrm{Kcal} / \mathrm{mol}$, sendo que o melhor resultado foi de $-7.44 \mathrm{Kcal} / \mathrm{mol}$.

Tabela 2. Energia de ligação (Kcal/mol) da rivastigmina estimada pelo programa ArgusLab

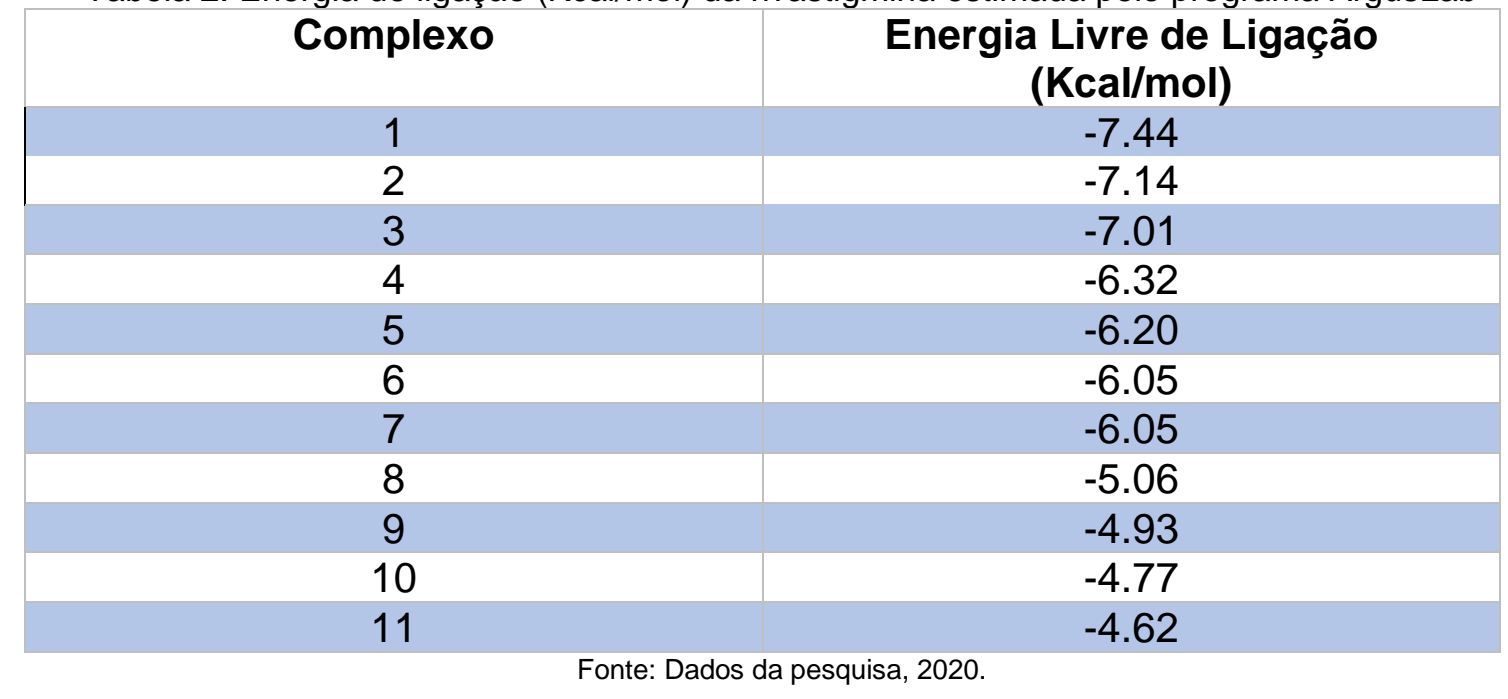

O sítio ativo da acetilcolinesterase é chamado sítio catalítico aniônico, fica localizado em uma região de cavidade aromática, tendo os aminoácidos Trp84 e Phe330 como contribuintes. No entanto, tem-se a presença de um segundo sítio, periférico aniônico, em uma região mais distante onde ficam localizados os resíduos Tyr70, Tyr121 e Trp279 (ALMEIDA 2011).

Através do programa Discovery Studio, foi possível visualizar em 2D a interação entre a rivastigmina e os aminoácidos localizados no sítio ativo da enzima (figura 4). Temos ligações do tipo Van der Waals (cor verde) com os resíduos Gly118, His440, e Ser200, ligação de pi (cor rosa) com o aminoácido Leu127 Trp84 e lle444. Também temos três antagonistas (cor vermelha) que 
estão afastando o ligante do sítio da proteína, são eles: Tyr130, Trp116 e Gly117.

No sítio ativo da enzima, os aminoácidos Ser200, His440 e Glu327, a chamada tríade catalítica, são considerados essenciais na atividade enzimática, por isso é de grande importância que os ligantes apresentem interações favoráveis com eles (HAREL, M. et al., 1993).

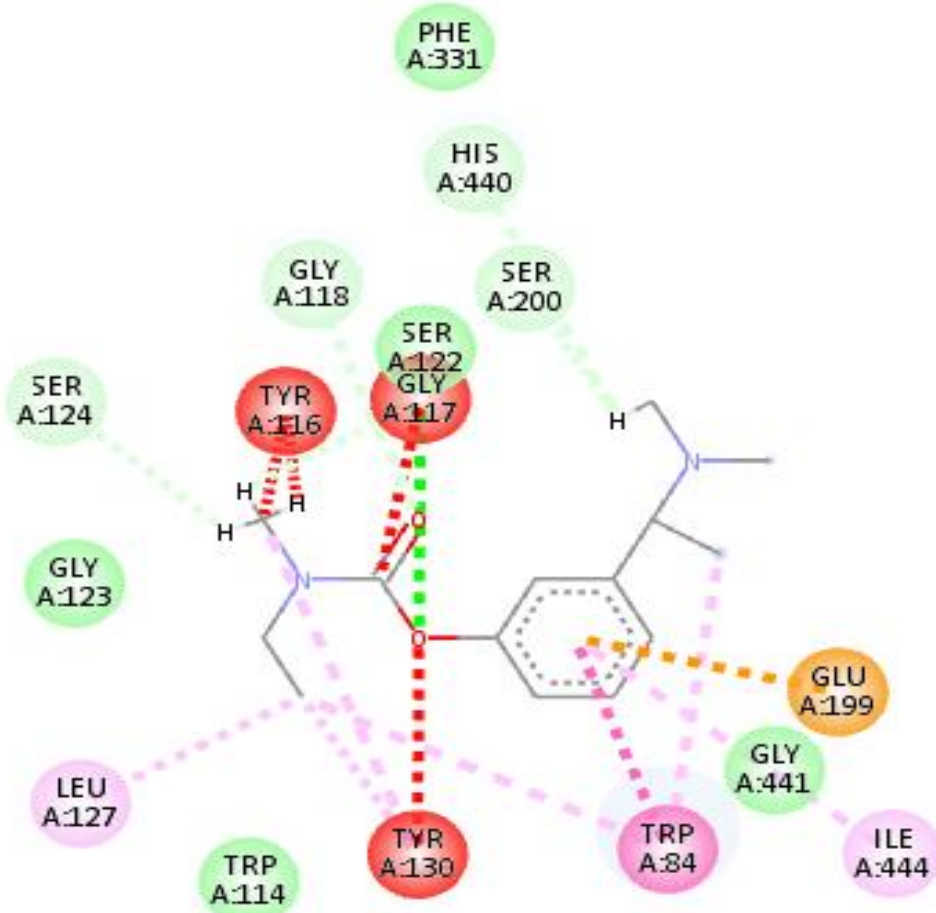

Figura 4. Visualização 2D do composto rivastigmina e os resíduos de $1 \mathrm{ACJ}$ de maior interação.

Fonte: Dados da pesquisa, 2020

A figura 5, gerada pelo programa Discovery Studio, ilustra a nuvem eletrostática envolvida na interação do ligante (rivastigmina) e o receptor 1ACJ. É fácil ver que o local de atracamento é em grande parte neutra, muito embora nas proximidades é possível notar uma certa negatividade, um dos aminoácidos responsáveis é o Trp84.

É importante ressaltar que, devido ao fato de as moléculas terem obtido um excelente ancoramento, tivemos então uma ampla variedade de resíduos interagindo com ligante.

Segundo (BAR-ON,P. et al., 2002), os locais de maiores picos positivos se devem aos aminoácidos Ser200 e Trp84. No entanto, em nossa amostra 
ilustramos justamente o contrário, onde tais resíduos se encontram em regiões de picos negativos.
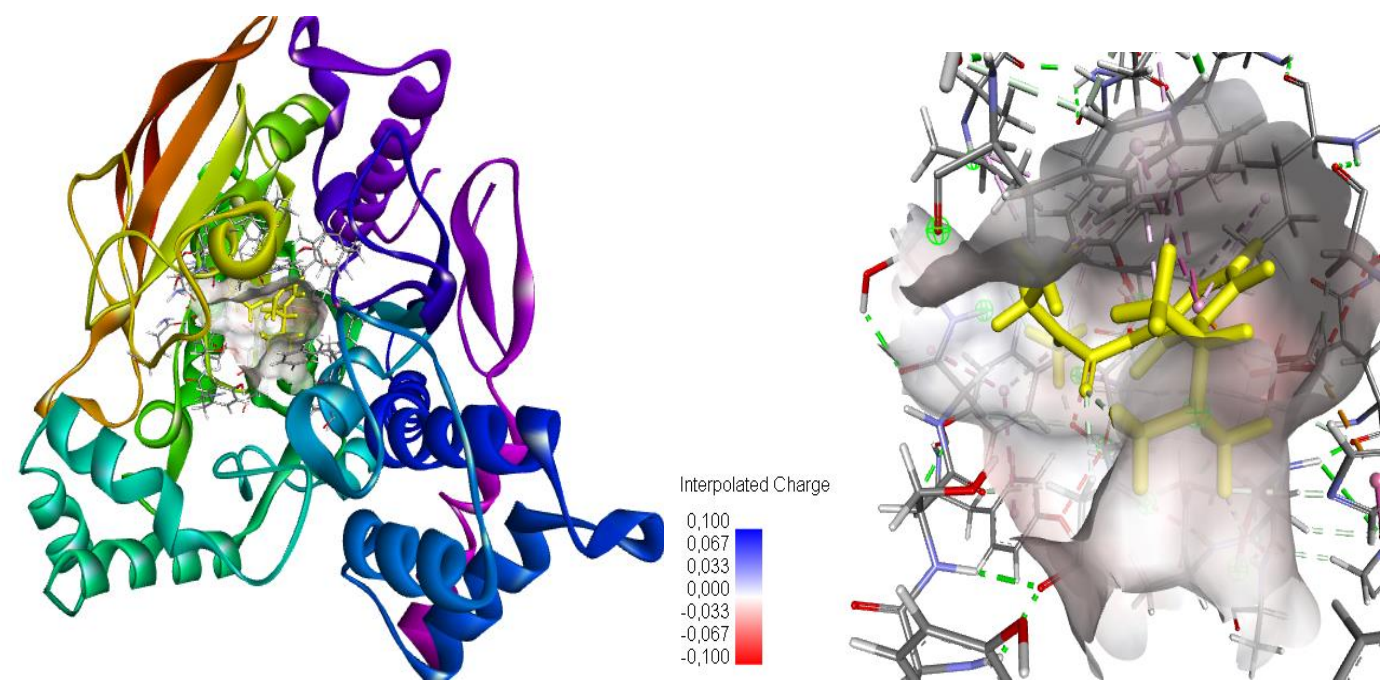

Figura 5. Enzima Acetilcolinesterase com o fármaco rivastigmina (amarelo) e a Nuvem interação eletrostática entre o receptor $1 \mathrm{ACJ}$ e o ligante

Fonte: Dados da pesquisa, 2020.

$\mathrm{Na}$ tabela II, podemos observar os dados gerados pelo programa Arguslab, onde trata-se das energias livres de ligação, obtidas em $\mathrm{Kcal} / \mathrm{mol}$, no processo de docking molecular. Neste caso, temos como ligante a galantamina, juntamente com o receptor $1 \mathrm{ACJ}$.

A conformação de atracamento escolhida foi a que o ligante se encaixou de forma flexível, neste caso foram apresentados os melhores resultados. Temos então que o menor valor calculado foi de $-9,08 \mathrm{Kcal} / \mathrm{mol}$, é importante destacar as posições oito e nove por obterem ambas a energia de $6,38 \mathrm{Kcal} / \mathrm{mol}$.

Na figura 6, também gerada pelo programa Discovery Studio, podemos visualizar em 2D, a interação entre a galantamina e os aminoácidos localizados no sítio catalítico e periférico da enzima. É possível observar ligações de tipo Van der Waals (verde claro), com dois dos resíduos que formam a tríade catalítica, Ser200 e His440, e no sítio periférico, com o Tyr121. Há também ligações de hidrogênio, tendo como contribuintes o Trp84 e o Glu199. 
Tabela 2. Energia de ligação $(\mathrm{Kcal} / \mathrm{mol})$ da galantamina estimada pelo

\section{Complexo}

\begin{tabular}{|c|c|}
\hline Complexo & $\begin{array}{c}\text { Energia Livre de Ligação } \\
\text { (Kcal/mol) }\end{array}$ \\
\hline $\mathbf{1}$ & -9.08 \\
\hline $\mathbf{2}$ & $-8,53$ \\
\hline $\mathbf{4}$ & $-7,21$ \\
\hline $\mathbf{5}$ & $-7,18$ \\
\hline $\mathbf{6}$ & $-6,85$ \\
$\mathbf{7}$ & $-6,75$ \\
\hline $\mathbf{8}$ & $-6,65$ \\
\hline $\mathbf{1 0}$ & $-6,38$ \\
\hline $\mathbf{1 1}$ & $-6,38$ \\
\hline & $-5,99$ \\
\hline
\end{tabular}

Fonte: Dados da pesquisa, 2020.

A galantamina fica localizada no fundo do desfiladeiro do sítio ativo, onde interage com o Trp84, entretanto a melhor forma de ligação seria com o His440. O aminoácido Phe330 é considerado flexível pela capacidade de obter diferentes conformações, apresentando interações cátion- $\pi$ ou empilhamento $\pi$, em contrapartida o Tyr121 se encontra fixado em toda estrutura, apresentando interação com grupos catiônicos e também como doador e receptor de ligações de hidrogênio (BARTOLUCCI, C. et al., 200). 


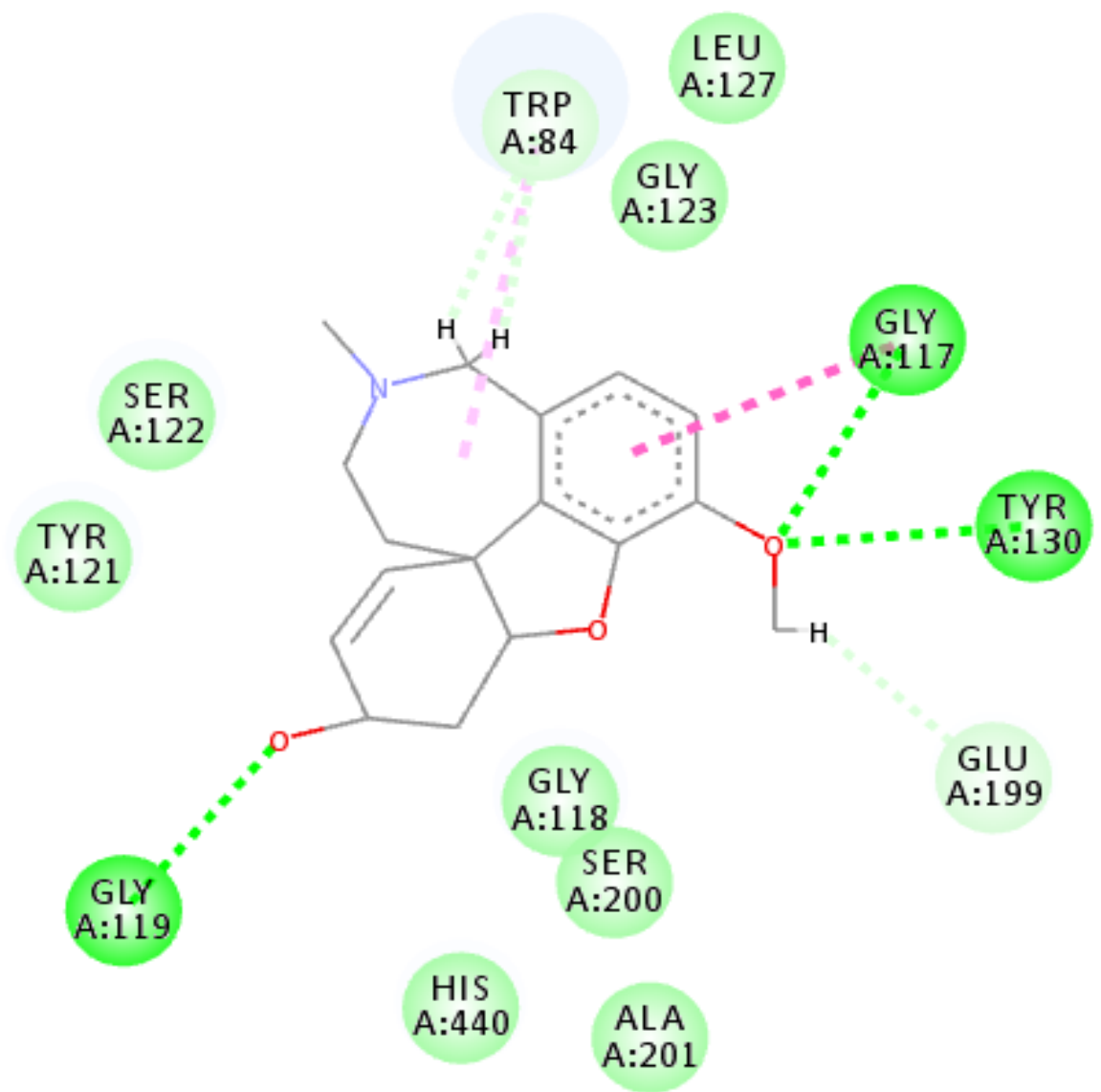

Figura 6. Visualização 2D do composto galantamina e os resíduos de 1ACJ de maior interação.

Fonte: Dados da pesquisa, 2020.

$\mathrm{Na}$ figura 7, gerada pelo programa Discovery Studio, a nuvem de interação eletrostática entre a galantamina e os aminoácidos do sítio ativo e o periférico da enzima. De acordo com a figura 7 a parte central do atracamento fica localizada em uma região de interação neutra, muito embora podemos notar que nas vizinhanças há uma certa negatividade eletrostática.

Em seu local de atracamento, o inibidor fica localizado no fundo da cavidade do sítio ativo, interagindo com o Trp84. A segunda interação é entre o grupo hidroxila do ligante com o resíduo Glu199. (DOUCET-PERSONENI, C. et al.,2001).

Assim como no caso da rivastigmina, também obtivemos um excelente encaixe com o receptor (1ACJ), visto que foram grandes os números de resíduos na interação proteína-ligante. 

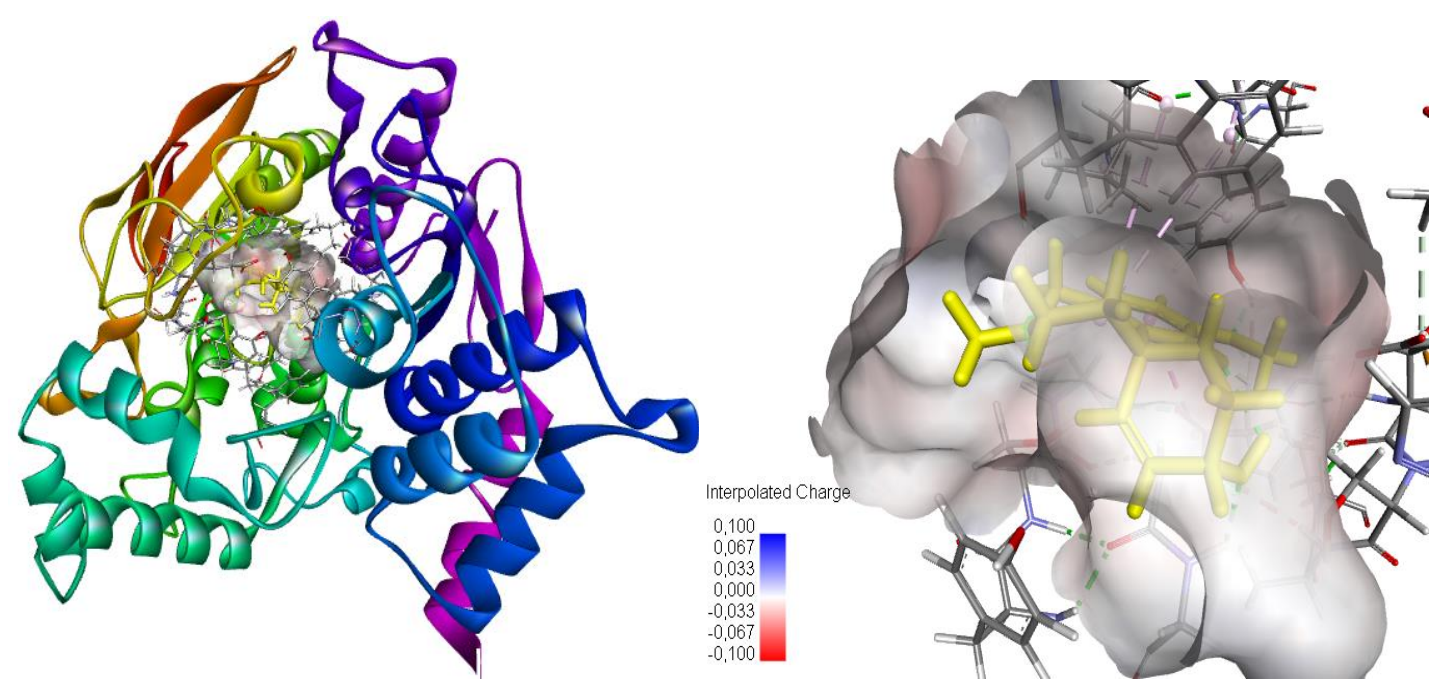

Figura 7. Enzima Acetilcolinesterase com o fármaco galantamina (amarelo) e a nuvem interação eletrostática entre o receptor $1 \mathrm{ACJ}$ com o receptor

Fonte: Dados da pesquisa, 2020.

\section{Conclusões}

Portanto, ferramentas computacionais vêm trazendo importantes contribuições nas descobertas de novas drogas e na validação de compostos já existentes. Este trabalho teve como intuito comprovar a eficiência dos inibidores da Acetilcolinesterase ao interagirem com sítio catalítico e periférico da enzima.

Em nossa análise, constatamos que os dois inibidores interagem de forma direta e eficaz com o receptor. Ao calcularmos as energias livres de ligação no processo de ancoramento, foi visto que os dois ligantes apresentam bons resultados, visto que as onze posições mostradas nas tabelas trouxeram baixas energias, isso mostra que o complexo formado entre as duas estruturas (proteína-ligante), são melhores juntas do que separadas.

As interações intermoleculares envolvidas nesse processo foram ligações de Van der Waals, ponte de hidrogênio e pi, muito embora tenha ocorrido nos dois complexos, a presença de aminoácidos antagonistas, que por sua vez, estavam afastando os ligantes do local de atracamento. Ambos ligantes obtiveram interação com dois dos aminoácidos pertencentes à tríade catalítica, Ser200 e His440.

Quando observadas as nuvens eletrostáticas envolvidas na interação dos ligantes próximos aos sítios, catalítico e periférico da molécula, foi 
constatado que o local de atracamento, era em maior parte neutra, apresentando picos de densidade negativos nas vizinhanças.

Dado o exposto, temos que os dois compostos apresentam atividades favoráveis para a inibição da Acetilcolinesterase, apresentando propriedades físico-químicas, capazes de atuar no Sistema Nervoso Central e inibir a ação enzimática.

\section{Referências}

ALMEIDA, Jonathan Resende. Estudos de modelagem molecular e relação estrutura-atividade da acetilcolinesterase $e$ inibidores em Mal de Alzheimer. 145 páginas.

Alzheimer's Association 2020. What is Alzheimer's Disease?. Acessado em < https://www.alz.org/alzheimers-dementia/what-is-alzheimers>. Em 14/09/2020

Alzheimer's Association. 2019 ALZHEIMER'S DISEASE FACTS AND FIGURES. Alzheimers Dement, volume 15

BAR-ON, P.; MILLARD, C. B.; HAREL, M.; DVIR, H.; ENZ, A.; SUSSMAN, J. L.; SILMAN, I. Kinetic and Structural Studies on the Interaction of Cholinesterases with the Anti-Alzheimer Drug Rivastigmine. Biochemistry (2002), 41(11), 35553564.

BARTOLUCCI, C.; PEROLA, E.; PILGER, C.; FELS, G.; LAMBA, D. Threedimensional structure of a complex of galanthamine (nivalin) with acetylcholinesterase from Torpedo californica: implications for the design of new anti-Alzheimer drugs. Proteins: Structure, Function, and Genetics (2001), 42(2), 182-191.

DISCOVERY STUDIO. Disponível em < https://www.3dsbiovia.com/products/collaborative-science/biovia-discoverystudio/>. Acessado em 23/04/2020.

DOUCET-PERSONENI, Caroline et al. A structure-based design approach to the development of novel, reversible AChE inhibitors. Journal of medicinal chemistry, v. 44, n. 20, p. 3203-3215, 2001. 
DRUG BANK. Disponível em < https://www.drugbank.ca/>. Acessdo em 14/09/2020.

Faculdade de Ciências Farmacêuticas de Ribeirão Preto/USP, Ribeirão Preto, 2011.

F. SOUSA, S. et al. Virtual Screening in Drug Design and Development. Combinatorial Chemistry \& High Throughput Screening, v. 13, n. 5, p. 442-

HENRIQUE, P.; BERTOLUCCI, F. ARTIGO Terapia Colinérgica na Doença de Alzheimer. Medicina, v. 8, n. 1, p. 11-14, 2000.

HAREL, M.; SCHALK, I.; EHRET-SABATIER, L.; BOUET, F.; GOELDNER, M.; HIRTH, C.; AXELSEN, P. H.; SILMAN, I.; SUSSMAN, J. L. Quaternary ligand binding to aromatic residues in the active-site gorge of acetylcholinesterase. Proceedings of the National Academy of Sciences of the United States of America (1993), 90(19), 9031-5.

NASCIMENTO, Samuel Andrade. Caracterização vibracional, termodinâmica e optoeletrônica de inibidores de Acetilcolinesterase. 160

MEHTA, M.; ADEM, A.; SABBAGH, M. New acetylcholinesterase inhibitors for Alzheimer's disease. Int J Alzheimers Dis, v. 2012, p. 728983, 2012.

PROTEÍNA DATA BANK. Disponível em: < https://www.rcsb.org/>. Acesso em Março e 2020.

RANG, H. . et al. Rang e Dale Farmacologia. [s.l: s.n.].

\section{Agradecimentos}

Ao CNPQ, ao Laboratório de Simulação computacional e Nanomateriais da UFCG/CES, Cuité-PB 